\title{
EFFICACY OF SALBUTAMOL DELIVERED THROUGH A METERED DOSE INHALER \& SPACER IN CHILDREN WITH ACUTE EXACERBATION OF ASTHMA
}

\author{
Ali Mujtaba Tahir, Waqas Akhtar*, Salah Ud Din Balooch**, Waqas Ahmed ${ }^{* * *}$, Ali Murtaza Samar***, Amina Sohail***** \\ Combined Military Hospital Zhob/National University of Medical Sciences (NUMS) Pakistan, *Combined Military Hospital Chhor/National University of \\ Medical Sciences (NUMS) Pakistan, ${ }^{* *}$ Combined Military Hospital Kharian/National University of Medical Sciences (NUMS) Pakistan, ${ }^{* * *}$ Combined Military \\ Hospital Dera Ismail Khan/National University of Medical Sciences (NUMS) Pakistan, ${ }^{* * * * S a l i s b u r y ~ D i s t r i c t ~ H o s p i t a l ~ N H S ~ T r u s t, ~ E n g l a n d, ~}{ }^{* * * * * C o m b i n e d}$ \\ Military Hospital / National University of Medical Sciences (NUMS) Rawalpindi Pakistan,
}

\section{ABSTRACT}

Objective: To assess efficacy of salbutamol delivered through metered dose inhaler (MDI) - spacer in paediatric patients with acute exacerbation of asthma.

Study Design: Prospective observational study.

Place and Duration of Study: Department of Paediatrics, Pakistan Naval Ship, Shifa Hospital, Karachi-Pakistan, from Jan to Dec 2018.

Methodology: Ninety Five patients aged $\geq 6$ to $\leq 12$ years, with acute asthma exacerbation were enrolled. Any patient with fever, clinical asthma score (CAS) $>7$, on home treatment with drugs delivered through nebulization or on oral steroids was excluded. Clinical asthma score recorded on presentation, followed with salbutamol via Metered Dose Inhaler \& spacer at dose of $400 \mu \mathrm{gm}(4 \times$ puffs of $100 \mu \mathrm{gm}$ ). Clinical asthma score rechecked after $20 \mathrm{~min}$. Response to salbutamol was then compared in relation to the presenting Clinical asthma score.

Results: Out of 95 children, 45 (47.9\%) were male \& 50 (52.1\%) female with $67.4 \%$ having positive family history for asthma. Average premedication clinical asthma score was 2.44 . Sixty nine $(72.9 \%)$ patients had an adequate response as they exhibited clinical asthma score of 0 or fall in score of $\geq 2$. Patients with adequate response had average clinical asthma score of 2.07 on presentation in contrast to 3.42 with inadequate response.

Conclusion: Salbutamol delivered via Metered Dose Inhaler \& spacer at dose of $400 \mu \mathrm{gm}$ is an effective medication for quick relief in children with acute exacerbation of asthma. Moreover, its administration at a point where exacerbation is not much severe steers us towards more favourable outcome.

Keywords: Asthma exacerbation, Clinical asthma score, Metered dose inhaler, Salbutamol, Spacer.

This is an Open Access article distributed under the terms of the Creative Commons Attribution License (http://creativecommons.org/licenses/by/4.0), which permits unrestricted use, distribution, and reproduction in any medium, provided the original work is properly cited.

\section{INTRODUCTION}

Asthma, a chronic entity commonly recognized in childhood, has a worldwide prevalence as it affects an estimated $8.3 \%$ children and distributed across all the socioeconomic groups ${ }^{1}$. It is characterized by periods of reversible airflow obstruction known as asthma attacks or exacerbations ${ }^{2}$. Asthma exacerbations are one of the leading causes of hospital admissions in paediatric population ${ }^{3}$. Asthma is the result of a complex interplay of immunologic, genetic and environmental mechanisms ${ }^{4}$. Inflammatory infiltration along with eosinophils and mucus hypersecretion as well as airway remodeling is usual characteristics - affecting its chronicity as well as severity ${ }^{5}$. These entangled factors phenotypically emerge as a disease after certain exposures including exercise, infection, allergens (e.g. pollen), occupational exposures and airborne irritants (e.g., environmental tobacco smoke) ${ }^{6}$. Risk limitation has a defining role in any asthma management stra-

Correspondence: Dr Salah Ud Din Baloach, Consultant Radiologist, Department of Radiology, CMH Kharian Pakistan

Received: 04 Jun 2020; revised received: 01 Aug 2020; accepted: 05 Aug 2020 tegy 7 . Presentation varies from recurrent wheeze to bronchitis, bronchiolitis, pneumonia and persistent cough with cold. This too is marked with periods of acute worsening of symptoms ${ }^{8}$. Current guidelines correlate the significance of preventive measures and optimal control ${ }^{9}$. Being a primarily clinical diagnosis, spirometry can be helpful in subtle presentations and in monitoring treatment response ${ }^{10}$. Pulse oximetry and emergency room measures remain as the cornerstone in treating hypoxemia. The important 4 cornerstones of asthma care include periodic assessment and monitoring, education, control of environmental factors/co-morbidities and lastly medications. The most utilized drug classes are $\beta 2$-adrenergic agonists, corticosteroids and leukotriene modifiers. Bronchodilators and corticosteroids can promptly assist in minimizing acute episodes, thus ensuring better quality of life appropriate to the age of the growing child with minimal functional and psychological morbidity. This study was conducted to evaluate the efficacy of short acting $\beta 2$-agonist (salbutamol) delivery via Metered Dose Inhaler \& spacer at low dosewith less potential sideeffects in acute worsening of asthma symptoms. 


\section{METHODOLOGY}

A prospective observational study was conducted in Emergency Department of Department of Pediatric Medicine, Pakistan Naval Ship, Shifa Hospital Karachi, Pakistan, from January to December 2018. It was meant to assess the presentation dynamics of acute exacerbation of asthma in children and efficacy of salbutamol delivered through Metered Dose Inhaler (MDI) during the exacerbation. A sample size of 95 patients was calculated using WHO sample size calculator keeping confidence level 95\%, anticipated population $47 \%$ and absolute precision $10 \% 10$. Patients were selected by non-probability consecutive sampling.

Severity of asthma exacerbation was assessed as per clinical asthma score (CAS) which involved assessment for presence of cyanosis, abnormal breath sounds, use of accessory respiratory muscles, inspiratory or expiratory wheeze and cerebral functioning status (table-I) with score ranging from 0-1015. Permission from the local ethics review committee was sought (ERC approval certificate number 2020/PAEDS/ 11). After informed written consent from each child's parents, 95 children with age $\geq 6$ years and $\leq 12$ years of either gender presenting to Paediatric Emergency Department were enrolled into the study by non-probability consecutive sampling. The younger children were excluded as drug delivery can be compromised without the use of face mask and hence the treatment efficacy. These children had presented in Emergency Department with acute exacerbation of asthma with CAS of 1-7 (accounting for mild to moderate exacerbation $)^{11-15}$. Assessment was done by on duty Paediatric Resident. Any child with fever (temperature $>100.4$ $\left.{ }^{\circ} \mathrm{F}\right)$, already diagnosed with a disease involving heart, kidney, liver or central nervous system, or with severe exacerbation of asthma with CAS $>7$ were excluded from the study. Likewise patients who were already on home treatment with drugs delivered through nebulization or on oral steroids were not included. After getting treatment history and family history, children were assessed clinically and scored on CAS on presentation. A quick demo-nstration of effective intake technique with MDI \& spacer was demonstrated by Paediatric Resident. This was followed with 4 puffs of salbutamol (i.e. total dose of $400 \mathrm{mcg}$ of salbutamol) administered through MDI and spacer. The patient's response was monitored on CAS after $20 \mathrm{~min}$ of intervention. Mean \pm SD calculated for quantitative variables like age, CAS on presentation and response to treatment after $20 \mathrm{~min}$. Post stratification chi square test applied. The $p$-value $\leq 0.05$ significant.

\section{RESULTS}

There were 95 patients of asthma with acute exacerbation who were taken into this study. Out of 95 patients, $45(47.9 \%)$ were male and $50(52.1 \%)$ female with male to female ratio 1:1.1.64 children $(67.4 \%)$ had positive family history for asthma. Among the 5 parameters of CAS, expiratory wheeze was the most common sign as it was witnessed in $79(83.1 \%)$ patients. It

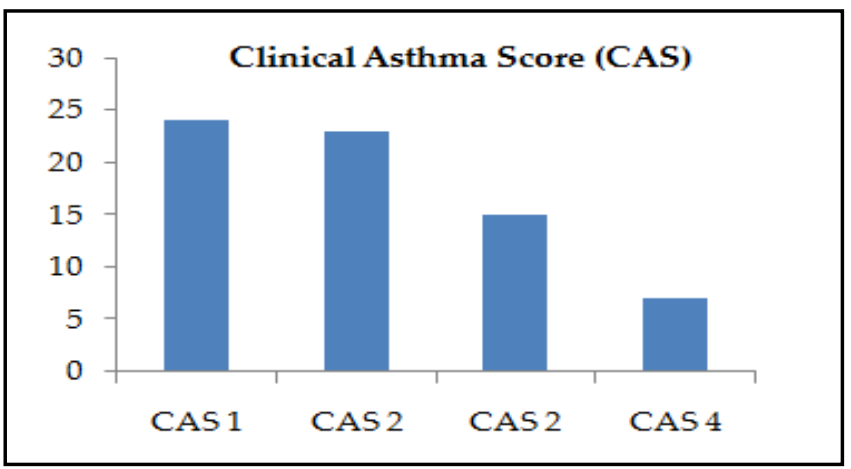

Figure-1: Clinical Asthma Score on presentation in patients with effective response to salbutamol with Metered Dose Inhaler \& spacer $(n=69)$.

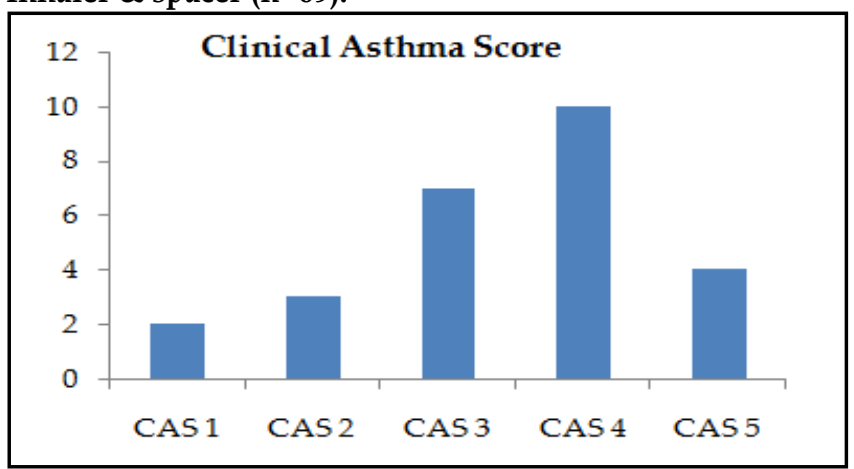

Figure-2: Clinical Asthma Score on presentation in patients with ineffective response to salbutamol with Metered Dose Inhaler \& spacer $(n=26)$.

was followed by subcostal recessions in terms of symptomatology as it was recognized in 39 children $(41.0 \%)$. Average CAS on presentation was found to be $2.44 \pm 1.19$. CAS was recorded after 20 minutes of salbutamol delivered via spacer \& MDI. 69 (72.6\%) patients had an adequate response to salbutamol, that is fall in CAS of $\geq 2$ or reduced to 0 after $20 \mathrm{~min}$. 26 $(27.4 \%)$ patients had documented inadequate response to salbutamol.

Patients who showed adequate response had mean CAS of $2.07 \pm 0.99$ while those who had an inadequate response showed mean CAS of $3.42 \pm 1.13$ 
on presentation $(p=0.0005)$. Eighty percent children with inadequate response had CAS of $>2$ on presentation as exhibited in fig- 2 . On the contrary $68 \%$ of children with adequate response showed CAS of $\leq 2$ on presentation as depicted in fig- 1 . Table-II shows the this wide variation is that our selected children were in acute exacerbation.

We observed average CAS on presentation in our patients was 2.44. Direkwatanachai et al also employed CAS for assessing asthma severity and reported aver-

Table-I: Clinical Asthma Score (CAS) ${ }^{15}$.

\begin{tabular}{l|l|l|l}
\hline \multirow{2}{*}{ Clinical Signs } & Clinical Asthma Score & $\mathbf{2}$ \\
\cline { 2 - 4 } & $\mathbf{0}$ & $\mathbf{1}$ & In FiO2 0.4 \\
\hline Cyanosis & No & In room air & Deceased or absent \\
\hline Abnormal breath sounds & Normal & Unequal & $\begin{array}{l}\text { Maximal (suprasternal + subcostal retraction } \\
\text { and/or flaring ala nasi) }\end{array}$ \\
\hline Accessory muscle use & No & Moderate (subcostal recessions) & Marked (inspiratory + expiratory wheeze) \\
\hline Wheeze & No & Moderate (expiratory wheeze) & Coma \\
\hline Cerebral function & Normal & Depressed or agitated & \\
\hline
\end{tabular}

stratification of response to salbutamol in relation to specific CAS on presentation. Majority were aged 6-9 years $(78.9 \%)$. However, the efficacy of salbutamol was identical in 6-9 \& $10-12$ years as $72 \%$ and $75 \%$ had the adequate response in these age groups respectively. Table-III depicts stratification in relation to age.

Table-II: Efficacy of salbutamol delivered with Metered Dose Inhaler \& spacer with respect to baseline Clinical Asthma Score ( $\mathrm{n}=95)$.

\begin{tabular}{|c|c|c|c|}
\hline \multirow{2}{*}{$\begin{array}{lr}\text { Clinical Asthma } \\
\text { Score } \\
\text { presentation }\end{array}$} & \multicolumn{2}{|c|}{ Efficacy } & \multirow[b]{2}{*}{$\begin{array}{c}p \text { - } \\
\text { value }\end{array}$} \\
\hline & $\begin{array}{c}\text { Yes } \\
\text { n (\%) }\end{array}$ & $\begin{array}{c}\text { No } \\
\text { n }(\%)\end{array}$ & \\
\hline $1-2$ & $47(49.5 \%)$ & $5(5.3 \%)$ & $<0.01$ \\
\hline $3-5$ & $22(23.2 \%)$ & $21(22.1 \%)$ & $<0.01$ \\
\hline
\end{tabular}

Table-III: Efficacy of salbutamol delivered with Metered Dose Inhaler \&spacerwith respect to age $(n=95)$.

\begin{tabular}{|c|c|c|c|}
\hline \multirow[b]{2}{*}{ Age } & \multicolumn{2}{|c|}{ Efficacy } & \multirow[b]{2}{*}{$\begin{array}{c}p \text { - } \\
\text { value }\end{array}$} \\
\hline & $\begin{array}{c}\text { Yes } \\
\text { n }(\%)\end{array}$ & $\begin{array}{c}\text { No } \\
\text { n }(\%)\end{array}$ & \\
\hline 6-9 years & $54(56.8 \%)$ & $21(22.1 \%)$ & \multirow{2}{*}{0.70} \\
\hline $10-12$ years & $15(15.8 \%)$ & $5(5.3 \%)$ & \\
\hline
\end{tabular}

\section{DISCUSSION}

Among our enrolled 95 children aged between 612 years, $52.1 \%$ patients were females and $47.9 \%$ were males, which show that incidence is nearly the same in two genders. Kamps et al while studying children 2-18 years of age, had also reported equal distribution of asthma in either gender in Netherlands as affected males were $49 \%{ }^{16}$. $67.4 \%$ of our patients were found to have a positive family history for asthma. Banjari et al reported that $75 \%$ of children aged 7-17 years with asthma in Jeddah had a positive family history ${ }^{17}$. $83.1 \%$ of our patients had expiratory wheeze. Matricardi et al had reported history of wheeze in $33.6 \%$ of their studied children ${ }^{18}$. However, the apparent reason behind age baseline CAS of 3.91 in their study carried out in Thailand in children aged 5-18 years ${ }^{14}$. This may reflect the fact that their patients were having more severe episode of exacerbation than ours.

We recognized $69(72.6 \%)$ patients had an adequate response, that is fall in CAS of $\geq 2$ or reduced to 0 after 20 minof administration of $4 \times$ puffs of salbutamol (400 $\mu \mathrm{gm}$ dose) delivered via Metered Dose Inhaler\& spacer. Twety six patients (27.4\%) had however an inadequate response. In contrast to this, Direkwatanachai et al had while using MDI \& spacer reported lesser efficacy of salbutamol delivered at dose of $600 \mu \mathrm{gm}$ as $47.1 \%$ of their patients had an adequate response after 20 minutes of intervention ${ }^{14}$.

We identified mean CAS of 2.07 on presentation in our patients who showed adequate response. In contrary our patients who had an inadequate response showed a mean CAS of 3.42 on presentation. This represents the fact that lesser the respiratory distress at the time of salbutamol administration delivered via MDI \& spacer, better the therapeutic effect is. In other words salbutamol should be administered early as soon as worsening of symptoms are noticed, otherwise effectiveness of salbutamol takes a downward trend. Likewise, $80 \%$ of children with inadequate response had CAS of $>2$ on presentation, while on the contrary $68 \%$ of children with adequate response showed CAS of $\leq 2$ on presentation. Salbutamol was found to be effective in $90.4 \%$ children whose CAS was 1-2 on presentation, while quite contrary to that efficacy reduced to $51.2 \%$ inchildren whose CAS was 3-5 on presentation. Thus, lesser CAS was associated with better therapeutic effects, meaning earlier it is used, more conducive the results are. Kamps et al while studying 47 subjects and utilizing Childhood Asthma Score, reported 83\% 
of their patients required admission whenever Childhood Asthma Score was $>416$.

\section{CONCLUSION}

Asthma is a common phenomenon in many families as the disease course of this chronic entity is marked with episodic exacerbations. Severe exacerbation does require management in the emergency department or even inpatient hospitalization ${ }^{16}$. Timely, yet effective, intervention can direct us towards limiting its morbidity and lesser hospital indoor stays. Salbutamol delivered via MDI \& spacer at the dose of $400 \mu \mathrm{gm}(4$ $x$ puffs of $100 \mu \mathrm{gm})$ is a ready choice as an effective medication for quick relief of worsening symptoms in asthamatic children - both at home and in hospital therapeutics. Earlier it is given on the severity ladder of exacerbation, more effective it is. Parental counseling with emergency management plan for home treatment with salbutamol delivered via MDI \& spacer should be integral part of every asthma management strategy.

\section{CONFLICT OF INTEREST}

This study has no conflict of interest to be declare by any author.

\section{REFERENCES}

1. Abul MH, Phipatanakul W. Severe asthma in children: evaluation and management. Allergol Int 2019; 68(2): 150-57.

2. Boulet LP, FitzGerald JM, Reddel HK. The revised 2014 GINA strategy report: opportunities for change. Curr Opin Pul Med 2015; 21(1): 1-7.

3. Saglani S, Menzie-Gow AN. Approaches to asthma diagnosis in children and adults. Front Pediatr 2019; 7(1): 148-58.

4. Link HW. Pediatric asthma in a nutshell. Pediatr Rev 2014; 35(7): 287-98.

5. Sima K, Ramratnam SK, Guilbert TW. Severe asthma in children. J Allergy Clin Immunol Pract 2017; 5(4): 889-98.

6. Myers JM, Schauberger E, He H, Martin LJ, Kroner J, Hill GM, et al. A pediatric asthma risk score to better predict asthma development in young children. J Allergy Clin Immunol 2019; 143(5):
1803-10.

7. Mirra V, Montella S, Santamaria F. Pediatric severe asthma: a case series report and perspectives on anti-IgE treatment. BMC Pediatr 2018; 18(73): 1-11.

8. Saglani S, Bush A, Carroll W, Cunningham S, Fleming L, Gaillard E, et al. Biologics for paediatric severe asthma: trick or treat? Lancet Respir Med 2019; 7(4): 294-96.

9. Falk NP, Hughes SW, Rodgers BC. Medications for chronic asthma. Am Fam Physician 2016; 94(6): 454-62.

10. Kalaycia O, Abdelateefb H , Beltránc CF, El-Sayedb ZA, Gómezd RM, Hossnyb E, et al. Challenges and choices in the pharmacological treatment of non-severe pediatric asthma: a commentary for the practicing physician. World Allergy Organ J 2019; 12(9): 54-63.

11. Papadopoulos NG, Custovic A, Cabana MD, Dell SD, Deschildre A, Hedlin G, et al. Pediatric asthma: an unmet need for more effective, focused treatments. Pediatr Allergy Immunol 2019; 30(1): 7-16.

12. Tesse R, Borrelli G, Mongelli G, Mastrorilli V, Cardinale F. Treating pediatric asthma according guidelines. Front Pediatr 2018; 6(1): 234-240.

13. Chipps BE, Bacharier LB, Farrar JR, Jackson DJ, Murphy KR, Phipatanakul $W$, et al. The pediatric asthma yardstick - practical recommendations for a sustained step-up in asthma therapy for children with inadequately controlled asthma. Ann Allergy Asthma Immunol 2018; 120(1): 559-79.

14. Direkwatanachai C, Teeratakulpisarn J, Suntornlohanakul S, Trakultivakorn M, Ngamphaiboon J, Wongpitoon N, et al. Comparison of salbutamol efficacy in children via the metered-dose inhaler (MDI) with Volumatic spacer and via the dry powder inhaler, Easyhaler, with the nebulizer--in mild to moderate asthma exacerbation: a multicenter, randomized study. Asian Pac J Allergy Immunol 2011; 29(1): 25-33.

15. Nievas IF, Anand KJ. Severe acute asthma exacerbation in children: a stepwise approach for escalating therapy in a pediatric intensive care unit. J Pediatr Pharmacol Ther 2013; 18(2): 88-104.

16. Kamps AW, Veeger NJ, Heijsman SM. An innovative childhood asthma score predicts the need for bronchodilator nebulization in children with acute asthma independent of auscultative findings. Respir Care 2014; 59(11): 1710-15.

17. Banjari M, Kano Y, Almadani S, Basakran A, Al-Hindi M, Alahmadi $\mathrm{T}$. The relation between asthma control and quality of life in children. Int J Pediatr 2018; 6(1): 1-6.

18. Matricardi PM, Illi S, Grüber C, Keil T, Nickel R, Wahn U, et al. Wheezing in childhood: incidence, longitudinal patterns and factors predicting persistence. Eur Respir J 2008; 32(3): 585-92. 